\title{
Aspectos climatológicos en las obras de funcionarios reales e ingenieros militares del siglo XVIII hispanoamericano/
}

\section{Climatologic subjects in the works of military engineers and royal officials of the Hispano-American \\ Eighteenth Century}

Juan Alberto Molina García

Universidad Politécnica de Madrid

En el siglo XVIII, los funcionarios reales y los ingenieros militares alcanzaron un considerable conocimiento de los climas americanos y de sus vínculos con aspectos de la realidad natural y social. Permanecieron durante largos períodos en las colonias hispánicas y los gobiernos les encomendaron la integridad del imperio y la resolución de asuntos relacionados con el clima. Sus procedimientos de indagación se basaron en la acción colectiva, así como en la división de tareas.

PALABRAS ClAVE: Clima; Funcionarios reales; Ingenieros militares; Informes oficiales; Utilidades.

In the Eighteenth century, royal officials and military engineers achieved a considerable knowledge of American climates and their links with several subjects of natural and social reality. They remained long periods at the Hispanic colonies and the governments commended them the wholeness of the Empire and the resolution of many business connected to climate. Their research procedures were base on the collective action, as well as on the division of tasks.

KEYwords: Climate; Royal officials; Military engineers; Official reports; Utilities. 


\section{Introducción}

Los ilustrados trataron las cuestiones referentes a la cultura y el medio geográfico con gran detalle y profundidad, alcanzando una honda comprensión de las sociedades y de las relaciones del hombre con su entorno natural. Así, en el siglo XVIII se consiguió un notable conocimiento del planeta en aspectos relativos a la diversidad natural, geográfica, etnográfica, sanitaria, cultural, política y administrativa; las corrientes ambientalistas vinculaban dichos aspectos al clima. ${ }^{1}$ Indagar en esos asuntos no sólo era cuestión de ideas y lecturas de documentos. Consistía, además, en una ardua labor basada en múltiples experiencias en las que no cabía de forma exclusiva la reflexión aislada de unos cuantos personajes sobresalientes, sino la acción colectiva y organizada de un gran número de interesados que, ubicados en diferentes lugares durante períodos temporales determinados, recababan datos diversos en los campos de operaciones y los hacían circular por vías expresas hasta un centro o sujeto coordinador. ${ }^{2}$

En este artículo se pondrá de manifiesto que una parte significativa del saber climatológico hispanoamericano del siglo XVIII se generó de forma social y organizada, en el seno del colectivo de funcionarios reales y de la colaboración de los ingenieros militares con éstos. En general, los miembros de dichas corporaciones tuvieron una excelente preparación académica y recibieron instrucciones para la buena administración política y económica de los territorios, la defensa de éstos, el trazado de las fronteras, el control jurídico de los habitantes y el fomento; en el transcurso de estas labores produjeron, manejaron, intercambiaron y transmitieron información científica —en particular, climática - de forma compartimentada, ordenada y jerárquicamente organizada; y para ello se valieron de distintos procedimientos de sencilla comprensión y rápido acceso.

1 Sobre dichos vínculos, véanse las obras de Urteaga, 1992; Glacken, 1996; Bowler, 1998. El caso particular de la relación entre clima y salud y la persistencia del pensamiento hipocrático en el siglo XVIII es analizado por Sargent, 1982.

2 Los recursos técnicos de carácter jerárquico que se emplearon en el mundo occidental medieval y moderno para efectuar investigaciones que requerían el acopio y tratamiento de grandes cantidades de datos, se explican en Guijarro Mora y González de la Lastra, 2010. En particular, el uso de tablas fue sumamente eficaz para manejar y transmitir información homogénea, pues su formato estandarizado y la evidencia proporcionada por las cantidades numéricas que hacían referencia a las observaciones, permitían sintetizar la información y establecer regularidades y correlaciones naturales a partir de las relaciones aritméticas. En la obra citada se dan ejemplos de los pasos seguidos por quienes elaboraron efemérides astronómicas, almanaques náuticos y tablas meteorológicas diseñadas por ciertas instituciones científicas de Alemania, España, Francia e Inglaterra. 
Es preciso señalar que dichos personajes también estaban interesados en recoger noticias fiables y útiles para quienes les siguieran en el ejercicio de sus labores; lo cual implicaba que sus conocimientos habrían de alcanzar un carácter familiar y acumulativo, de modo que sirvieran a más personas comprometidas en aquellas funciones. Es decir, el saber adquirido debía ser susceptible de ponerlo a disposición de otros personajes dispuestos a utilizarlo convenientemente, a no introducir alteraciones sustanciales que desvirtuaran su mensaje originario y a utilizarlo de forma oportuna para dominar espacial y cronológicamente los territorios objeto de estudio y gobierno. ${ }^{3}$

El hecho de haber elegido el mundo hispánico de la Ilustración para el debate de los asuntos que aquí se abordan se justifica por la especial relevancia que el saber climatológico adquirió en dicho marco histórico y geográfico. En efecto, el imperio español alcanzó en el siglo XVIII su máxima extensión y, respecto a las centurias precedentes, hubo un aquilatado incremento del apoyo institucional a las ciencias y las técnicas. Esto hizo que surgiera la necesidad de garantizar la integridad física de los territorios hispánicos y de resolver un sinfín de cuestiones relacionadas con la naturaleza y, de modo específico, el clima. Para llevar a término esos cometidos, la corona disponía de suficientes recursos humanos y económicos, además de los necesarios conocimientos científicos y técnicos. Y es que, dada la amplitud de los dominios en cuestión y la cantidad y complejidad de los intereses que se debían atender, obtener y manejar cualquier tipo de información aconsejaba la intervención de muchos observadores afanados en la toma, registro, análisis, transmisión y comparación de datos.

\section{Antecedentes}

Desde los momentos inmediatamente posteriores al descubrimiento de América, y hasta el fin de la etapa colonial, las autoridades virreinales y otros personajes al servicio de la corona estaban obligados a realizar visitas periódicas a los territorios hispánicos, inspeccionar los asentamientos y levantar actas de sus pesquisas. Fue este uno de los procedimientos ideados por los monarcas españoles para recabar información sobre sus posesiones ultramarinas; el grado de implicación de los partícipes en la indagación

3 Lo expresado en este párrafo está presente a lo largo del texto y se basa en Latour, 1992, 205-243. 
climatológica fue variable. En general, tanto los protocolos empleados como los resultados obtenidos fueron homogéneos. Además, se nombraron cronistas e historiadores oficiales que intervinieron directamente en los hechos históricos y en las observaciones de carácter naturalista; o bien, ajenos a unos y otras, recopilaron una gran cantidad de información y dieron lugar a la producción de obras de considerable envergadura. ${ }^{4}$

Las normas e instrucciones oficiales se sucedían en orden descendente, y el trasvase de información en el contrario. De modo que las iniciativas metropolitanas tenían cumplidas respuestas en las cortes virreinales, y de ahí pasaba a los estratos inferiores hasta los encargados de realizar las consultas e investigaciones de campo. A partir de éstas, se confeccionaban informes y crónicas que habían de pasar por el visto bueno de los superiores jerárquicos, el consejo de Indias, la censura y la realeza. ${ }^{5}$ Así, mientras que en España se registraba el saber derivado de las noticias llegadas del lado opuesto del océano, las Indias occidentales se convirtieron en el lugar de observación donde muchos interesados, impulsados por motivos o mandamientos diferentes, realizaban estudios sobre la naturaleza, el clima, la sociedad, la historia y la cultura. Con el transcurrir del tiempo, los funcionarios, ingenieros, historiadores y cronistas vinculados a la administración real aceptaron unos esquemas de trabajo de tendencia ambientalista; dichos esquemas incluían la posición geográfica, la calidad atmosférica del lugar, el clima, los ríos, las aguas, los montes, las minas, los minerales, los productos vegetales, los animales, el origen y la situación de las ciudades, las autoridades locales, la salud, las enfermedades y las epidemias. ${ }^{6}$ Durante los siglos XVI y XVII fue considerable la cantidad de manuscritos y obras impresas que contenían estudios geográficos y naturalistas; esos documentos incluían en sus páginas descripciones y explicaciones sobre las causas de los climas americanos. ${ }^{7}$

4 Sobre el cuerpo legislativo que Carlos II mandó recopilar en 1682 y que centró la atribución de funciones a cronistas mayores y cosmógrafos reales, así como otros contenidos de las actividades humanas en las Indias occidentales, véase López Pozo, 1995.

5 Acerca de la labor científica desempeñada por el consejo de Indias y sus procedimientos jerárquicos de obtención y transmisión de datos, véase Schäfer, 2003, 351-379.

6 La relación entre el medio geográfico, el natural y las condiciones climatológicas de una región, establecida por los primitivos cronistas de Indias, es analizada por Muñoz Pérez, en Solano y Pino, 1982, 135-188.

7 Especial mención merece el estudio sobre la interacción entre los climas y las características geográficas y naturales de América efectuado por Acosta, 1590. El jesuita quiso acentuar la unidad indisociable entre ambos mundos y defendió que la naturaleza americana tenía sus propias características distintivas, si bien participaba de la generalidad del todo común. El libro de Acosta ejerció una 


\section{Funcionarios reales e ingenieros militares del siglo XVIII. Algunos proyectos de alcance climatológico}

En el siglo XVIII, como en los dos precedentes, la realidad imperial española fue un factor condicionante de la actividad científica de la metrópoli y de las colonias ultramarinas. Dicha actividad estuvo sujeta a las particulares circunstancias históricas, culturales, religiosas y económicas por las que atravesaron las sociedades española e iberoamericana hasta finales de la centuria. ${ }^{8}$

Tras la Guerra de Sucesión, en efecto, los Borbones empezaron a fomentar el cultivo de las ciencias a expensas de las viejas instituciones. Pero pusieron al frente de éstas a actores nuevos que no eran sino profesionales cuyo ascenso social se basaba en la formación académica y el talento propio, antes que en la alcurnia. Con el paso del tiempo, las directrices generales de las prácticas científico-técnicas giraron alrededor de la propia estructura administrativa estatal y el mantenimiento de las colonias ante la creciente agresividad de Francia, Holanda, Inglaterra, Portugal y Rusia. La ciencia y la técnica española de la Ilustración se trasladaron a Iberoamérica y se convirtieron en herramientas útiles para las reformas y la salvaguarda estratégica del imperio; y sus protagonistas adquirieron una importancia esencial en la toma de decisiones políticas y geoestratégicas. ${ }^{9}$

En América, además, funcionaban otros aparatos burocráticos — cortes virreinales e iglesia - que sostuvieron un permanente esfuerzo de reconocimiento de las realidades naturales de los territorios y gozaron de cierta autonomía política y financiera. De ahí que pudiesen promover con éxito variable sus propias iniciativas científicas. En algunas ocasiones colaboraron con los proyectos de la corona; otras veces actuaron según unos obje-

gran influencia durante varios siglos y fue traducido a algunos idiomas europeos. Desde el punto de vista historiográfico, su obra pertenecía a un género que proporcionaba la pauta a seguir en la temática de las relaciones geográficas y las historias naturales y morales, pues se basaba en la continuidad existente entre todos los elementos naturales y en la sustentación de lo moral sobre lo natural. Véase Aguirre, 1957, 176-187.

8 Sobre las vicisitudes sociales, políticas y económicas por las que atravesaron España y sus colonias al afianzarse la dinastía borbónica en el poder, la entrada de las ideas ilustradas en la península ibérica y las reformas borbónicas, véase Kamen, 2003. De modo más específico, se estudia el proyecto de renovación de los Borbones en España e Iberoamérica en Guimerá, 1996.

9 Los siguientes autores se han ocupado de la institucionalización del saber científico: Lafuente y Peset, en Sellés, Peset y Lafuente, 1988, 29-80; Capel, en Ibidem, 99-126 y 187-204. En cuanto al dominio de la ciencia por los militares durante el segundo cuarto del siglo XVIII, véase Lafuente y Peset, en Peset, 1986, 127-147. Acerca del traslado de la ciencia española a las colonias, véase Lafuente y Sala Catalá, 1992; también, Martínez Sanz, 1992. 
tivos diferentes de los planes auspiciados por ésta, obedeciendo a circunstancias puramente endógenas, aunque debieron contar con su beneplácito. ${ }^{10}$

Con este panorama de fondo, puede afirmarse que durante el siglo XVIII hubo una considerable actividad climatológica en las colonias españolas de ultramar. Algunos de sus artífices fueron funcionarios reales e ingenieros militares que desempeñaron las labores encomendadas por los gobiernos y que, con el fin de hacer viables sus trabajos, guiaron sus actuaciones según determinados procedimientos que se verán más adelante. El clima interesó a aquellos colectivos por su relación con otros fenómenos naturales y morales ${ }^{11}$ sus aplicaciones prácticas —en medicina, agricultura, ganadería, náutica e hidrología - y su repercusión en la toma de decisiones. La información climática manejada, junto con toda la demás, se difundió a través de relaciones geográficas, informes oficiales, correspondencia epistolar, historias naturales y morales y obras cosmográficas. Es preciso aclarar, no obstante, que los integrantes de dichos colectivos estaban sometidos a una fuerte disciplina y que la mayor parte de ellos no aspiraban a transmitir a través del mundo editorial sus trabajos; el objetivo, más bien, era poner éstos en conocimiento de los superiores jerárquicos; de ahí que, con excepciones, muchos de los textos aquí comentados se hayan conservado en forma manuscrita durante décadas, o incluso siglos, y sólo en épocas relativamente recientes se haya visto la conveniencia de imprimirlos. ${ }^{12}$

Los funcionarios reales, el primero de los colectivos considerados, cumplieron un papel de extraordinaria importancia en la política territorial, defensiva, administrativa y económica de los virreinatos. Muchos de ellos tuvieron una ascendencia modesta, se integraron en la milicia y llegaron a obtener títulos nobiliarios como gratificación por sus valiosos servicios a la corona. Sus acciones se apoyaron en diversos procedimientos para recabar y transmitir datos valiosos a sus superiores. Así, hay pruebas de que recurrieron al sistema de cuestionarios y relaciones geográficas ${ }^{13}$ para obtener y transmitir información de todo tipo. Pero también efectuaron visitas e inspecciones a los territorios y recabaron informes de sus subordinados.

10 La intervención de tres tradiciones científicas (metropolitana, virreinal y eclesiástica) en la ciencia americana ha sido tratada por Lafuente y López-Ocón Cabrera, en Saldaña, 1996, 247-281.

11 Los fenómenos morales eran los que concernían a las características psíquicas, sociales, culturales, etnográficas, religiosas, éticas, estéticas, políticas, etc., de los seres humanos.

12 Capel, Sánchez y Moncada, 1988, 341.

13 El sistema de cuestionarios y relaciones geográficas fue una herramienta eficaz, duradera y de uso generalizado para la obtención y transmisión de datos climáticos y de otro tipo. Véase al respecto Altolaguirre y Duval, 1954; Solano y Ponce Leiva, 1988a; Solano, 1988b; Solano, 1995. 
Un caso particular fue el de las memorias emitidas por los virreyes, que desde la promulgación de las célebres Ordenanzas Reales de 1572 estaban obligados a enviar al consejo de Indias. Se trataba de informes que los mandatarios emitían al abandonar el poder y cedérselo a sus sucesores. Estos documentos eran de suma utilidad y tenían su origen en las continuas consultas de informes y expedientes que se conservaban en las secretarías de los virreinatos; incluían aspectos concernientes a las peculiaridades naturales y climáticas de los territorios que afectaban a las actividades económicas, políticas, educativas, sanitarias, defensivas, etc. Casi todos ellos parecían cortados por el mismo patrón, solían tener un carácter apologético, descriptivo y misceláneo y servían para componer un cuadro de conjunto del estado de los virreinatos. Los del siglo XVIII, concretamente, ponían de manifiesto el dinámico impulso reformista de los Borbones, y con frecuencia invocaban los informes de los virreyes precedentes. Estos textos, por el imperativo de la distancia y la necesidad de disponer urgentemente de noticias fidedignas procedentes de ultramar, tuvieron un carácter exclusivamente indiano..$^{14}$

Véanse seguidamente algunos ejemplos representativos de funcionarios reales que incluyeron información climática en sus obras.

En los tiempos de la expedición geodésica a Perú, Dionisio de Alsedo y Herrera ejercía como presidente de la audiencia de Quito. ${ }^{15}$ Alsedo produjo una serie de obras ${ }^{16}$ que perseguían el doble objetivo de informar al rey acerca de los asuntos de América y denunciar el contrabando inglés. Estos escritos fueron producto de una estancia de más de cuarenta años en el Nuevo Mundo, así como de las lecturas de relaciones geográficas y crónicas de Indias; y contenían una abundante información climatológica local y territorial. El autor relató sus viajes por el continente y dio razón de sus observaciones personales y de su colaboración con Charles Marie de La Condamine, Jorge Juan y Antonio de Ulloa.

En otro ámbito geográfico, Manuel Amat y Junyent, virrey de Perú ordenó en 1772 al capitán Domingo Boenechea que emprendiera una expedición a las islas de Amat (Tahití) San Carlos (Pascua); el marino se interesó por el estudio de las riquezas naturales y de las características geográficas de ambos enclaves. El encargado de redactar los informes

14 García y García, 1869; Radaelli, 1914; Lohmann Villena, 1959; Calderón Quijano, 1967.

15 Sobre la expedición geodésica, véase Lafuente y Mazuecos, 1978.

16 Alsedo y Herrera, 1741, 1766 y 1771. 
correspondientes $^{17}$ fue el capitán de navío José Andía y Varela, quien los remitió a Amat; después, éste se vio en condiciones de completar su propia obra $^{18}$ y de incluir en ella descripciones climáticas del reino de Chile y de las islas adyacentes.

Algo similar ocurrió cuando Jerónimo Matorras, general del ejército y gobernador de Tucumán, entró en la región del Chaco. Durante el siglo XVIII, en efecto, la corona española, presionada por Portugal y otras potencias europeas, se vio obligada a penetrar en determinadas regiones americanas insuficientemente controladas y donde había intereses políticos, estratégicos y económicos en liza. Por la Real Contrata de 1776, Matorras se comprometió a explorar los territorios chaqueños, pacificar a los indios, organizarlos en reducciones y establecer comunicaciones entre Tucumán, Corrientes y Asunción. El escribano Blas Joaquín Brizuela formó parte de la misión y dispuso de varios documentos ${ }^{19}$ con los que pudo componer su propia visión de aquellos hechos. ${ }^{20}$ La obra en cuestión contenía información climatológica.

Por otro lado, entre las obligaciones impuestas a los gobernadores e intendentes virreinales en virtud de la Real Ordenanza que los instituyó en 1782, estaba la de recorrer cada uno de sus departamentos para fomentar la agricultura, la industria y el comercio. Los altos funcionarios debían observar la realidad natural, demográfica y económica de los territorios. Para realizar esta tarea, recurrían a la colaboración de informantes y subordinados y se amparaban en documentos de sus predecesores. Por Real Orden del 10 de mayo de 1784, los virreyes debían elaborar informes semestrales sobre asuntos agrícolas y sanitarios, proporcionando información acerca del tiempo atmosférico experimentado en las diferentes provincias de los territorios bajo su administración. Así, en 1785 Juan del Pino Manrique, gobernador de Potosí, dirigió a José Gálvez un informe descriptivo ${ }^{21}$ de la provincia de Tarija, término austral del imperio inca. Más tarde envió al virrey de Perú, el marqués de Loreto, un escrito ${ }^{22}$ similar.

A veces, los funcionarios reales facilitaban a otros personajes al servicio de la corona alguna información de interés. Por ejemplo, cuando el ingeniero militar Félix de Azara quiso recoger materiales para elaborar una

17 Andía y Varela, 1774.

18 Amat, 1775.

19 Entre otros, el del padre Lozano, 1773.

20 Brizuela, 1776.

21 Pino Manrique, 1785.

22 Pino Manrique, 1787. 
historia política y natural de Paraguay, solicitó a Gonzalo de Doblas, gobernador de la provincia de Misiones, un informe preciso $^{23}$ sobre el origen y los progresos de los indios y sobre cuestiones climatológicas referentes al carácter moral y las costumbres de éstos. El alto funcionario, que había examinado con esmero a los nativos, indicó las posibles soluciones que les sacarían de su abatimiento; lo que aprovechó Azara para completar sus estudios y afianzar sus propias ideas al respecto. Doblas, además, envió copias de su propio trabajo a los virreyes Loreto y Avilés y a los brigadieres Diego Alvear y José Varela; el último lo puso en conocimiento del rey, quien mostró su aprobación y disposición a poner en práctica el plan diseñado por el autor.

Otras veces, los funcionarios reales, con objeto de poner a punto algún plan reformista, efectuaban estudios sobre determinadas regiones. Así, Francisco de Viedma, gobernador intendente de Buenos Aires, redactó en 1788 una respuesta a la Orden del día 13 de octubre de 1787 por la que el virrey, Nicolás de Arredondo, le pedía una relación geográfica ${ }^{24}$ de la capital y sus partidos. El informe había de dar cuenta de los temperamentos o grados de calor, la población, las razas, los cultivos, los frutos, los alimentos, las calidades de los terrenos, los ganados y otros asuntos.

Los ingenieros militares, por su parte, prestaron sus servicios a los funcionarios reales en labores referentes al fomento, la defensa de los territorios y la explotación de los recursos naturales; en ellas entraban en consideración las condiciones climáticas. ${ }^{25}$ Dichos personajes, repartidos por varios lugares, se regían por pautas de trabajo comúnmente admitidas, como observaciones directas, mediciones instrumentales ${ }^{26}$-en tal caso, registro tabular de variables atmosféricas, realización de cálculos sencillos con las cantidades y búsqueda de regularidades y correlaciones climáticas apoyadas en regularidades y correlaciones numéricas-, realización de descripciones y comparaciones climáticas, elaboración de informes y remisión de éstos a las autoridades. Además, lo mismo que los funcionarios reales,

23 Doblas, 1785.

24 Viedma, 1788.

25 Algunas obras interesantes sobre las funciones de los ingenieros en la metrópoli y en las colonias son las siguientes: Capel, Sánchez y Moncada, 1988; Capel y Casals Costa, en Peset, 2002, 569-602; Capel, en Varios Autores, 2005, 83-132.

26 Sobre la invención y funcionamiento de los instrumentos meteorológicos, véase Middleton, 1969. En cuanto a la relativa facilidad para manejarlos y el rol desempeñado por ellos para replicar experiencias, formar conocimiento de modo consensuado y compartirlo inequívocamente, véase Valverde Pérez, 2007. 
tenían la posibilidad de consultar datos y documentos en archivos oficiales, prensa periódica, instituciones científicas y académicas, consulados y sedes eclesiásticas. Y compartían determinados códigos de comunicación, como la propia lengua y términos científicos comúnmente aceptados.

Dada su buena preparación académica, dedicación plena, fidelidad a la monarquía y disponibilidad para dirigirse a los lugares que se les indicara, fueron muchos los territorios ultramarinos donde los ingenieros militares hicieron acto de presencia. Al acabar el siglo XVIII estaban repartidos de la siguiente manera: 54 en México; 29 en Cuba, Puerto Rico, Santo Domingo y Trinidad; 8 en Florida, Luisiana y Texas; 13 en Guatemala, Honduras, Costa Rica y Nicaragua; 29 en Colombia, Ecuador, Venezuela y Panamá; 22 en Argentina, Paraguay y Uruguay; 22 en Chile y Perú. ${ }^{27}$ En el marco de la política defensiva de la corona, los ingenieros militares estaban obligados a cumplimentar descripciones de los territorios donde ejercieron sus tareas. De los climas americanos les interesaron sus peculiaridades locales y los repartos zonales y cronológicos; también se fijaron en su interacción con otros fenómenos naturales y geográficos, así como su influencia en los seres vivos; por último, prestaron atención al régimen hidrológico; dichos aspectos fueron incluidos en sus obras y formaron parte de un estudio amplio de los territorios y de las sociedades que conocieron. Las aplicaciones prácticas de estos trabajos se centraban en las planificaciones agrícolas, el establecimiento de divisiones territoriales según las características climáticas, la puesta a punto de proyectos urbanísticos, el aprovechamiento del agua meteórica y la implantación de normas jurídicas con arreglo a las peculiaridades etnográficas y morales de la población. Se comentarán a continuación algunos ejemplos.

La década de 1770 fue especialmente agitada para el ingeniero militar Francisco Manuel Policarpo Requena y Herrera por la cantidad de cargos oficiales y tareas que tuvo que asumir. Después de su llegada a Panamá en 1764, Requena residió y trabajó en América durante más de treinta años, permanentemente ocupado en proyectos cartográficos y de arquitectura militar. En 1769 el virrey Pedro Messía de la Cerda le ordenó que viajara a Guayaquil para dibujar los planos de la ciudad y trabajar en su fortificación. Requena sobrepasó las órdenes recibidas y escribió una obra $^{28}$ en la que, entre otras cosas, ofrecía su visión del clima del país. El ingeniero

27 Capel, Sánchez y Moncada, 1988, 322.

28 Requena, 1774. 
militar se sirvió de los informes de las autoridades provinciales, sus propias observaciones, su correspondencia epistolar con el priorato franciscano de Perú y las crónicas y relaciones de viajes de autores contemporáneos y pretéritos (Francisco López de Gómara, el inca Garcilaso de la Vega, Dionisio de Alsedo, Charles Marie de la Condamine, William Dampier, Laurent Echard, José Gumilla, Jorge Juan, Antonio Ulloa y otros). Además, envió a sus subordinados un formulario con el que debían dar razón de los territorios donde ejercían sus funciones y devolvérselo debidamente cumplimentado en el menor tiempo posible; él mismo se encargó de analizar posteriormente la información y de redactar sus conclusiones. ${ }^{29}$

Por otro lado, la parte septentrional de Nueva España adquirió un alto valor estratégico durante el siglo XVIII, pues era la frontera del imperio y confluían en ella los intereses de Inglaterra, Francia y Rusia. Como medida de control de dicho territorio, la corona ordenó la ocupación de las costas californianas, reorganizó la línea de los presidios y estableció una comandancia general de las provincias internas; bajo el mando de altos funcionarios reales, los ingenieros militares intervinieron en estas acciones. Uno de los primeros fue Francisco Álvarez Barreiro, quien formó parte de la expedición del virrey de Nueva España, marqués de Valero, a Texas en 1717. Entre 1724 y 1728, Barreiro acompañó al brigadier Pedro de Rivera en la inspección de los presidios de la frontera norte. Producto de esta segunda empresa fueron varios planos de la zona y una obra adjunta ${ }^{30}$ que contenía descripciones climáticas de la región.

En marzo de 1768, Miguel Costanzó recibió la orden de Carlos Francisco de Croix, virrey de Nueva España, de trasladarse al puerto de San Blas, donde debía esperar al visitador José Gálvez; después, ambos habrían de trasladarse a Monterrey. Una vez en su destino, el ingeniero barcelonés reconoció el territorio, levantó planos del puerto y dirigió las obras de construcción de un fuerte. Costanzó dejó memoria escrita de ello ${ }^{31}$ hizo una descripción detallada de las condiciones naturales y climáticas de la región y comentó las costumbres de la población indígena. ${ }^{32}$

En ese mismo contexto y ámbito geográfico, el capitán de ingenieros Nicolás de Lafora escribió un informe ${ }^{33}$ a resultas de la expedición enco-

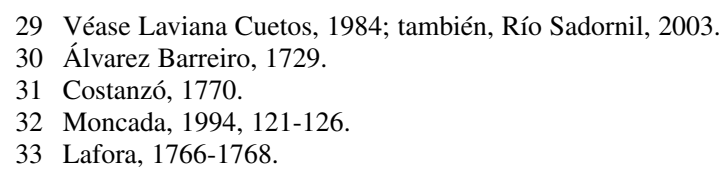


mendada al marqués de Rubí con el fin de reconocer los presidios internos y proponer mejoras para su defensa. Lafora incluyó datos sobre la población, los recursos económicos, los pobladores, el clima, la vegetación, la fauna, la conformación urbanística, las riquezas minerales y agrícolas, los ríos y otras particularidades referentes a la geografía física y humana del norte de Nueva España. En particular, prestó una gran atención a la ubicación de los presidios, pues consideró que algunos de ellos se habían construido apresuradamente, sin tomar en cuenta las condiciones geográficas, climáticas y salutíferas del lugar. ${ }^{34}$

Otro de los ingenieros militares destinados a la misma área territorial para realizar tareas similares fue Juan de Pagazaurtundúa, originario de México pero formado en España. Éste envió una relación ${ }^{35}$ al teniente general Luis Huet en la que relataba sus experiencias entre los años 1782 y 1796. Incluyó en ella descripciones de ciertos territorios novohispanos, señaló sus condiciones naturales y climáticas y realizó estudios sobre la población indígena. La composición del informe fue posible gracias a sus propias observaciones, las consultas de fuentes diversas, las entrevistas con clérigos y funcionarios, el intercambio de datos con otros colegas y la reflexión sobre las respuestas dadas a los cuestionarios geográficos. Se han localizado reportes similares, efectuados por diversos autores, sobre los territorios de Nuevo Santander, ${ }^{36}$ Yucatán, ${ }^{37}$ Arizpe $^{38}$ y Cuba. ${ }^{39}$

Algunas iniciativas de investigación de los climas americanos fueron producto de inquietudes personales. Ese fue el caso de Félix de Azara y Perera. Al margen de la misión inicial que se le encomendó - en 1781 formó parte de la comisión de límites entre España y Portugal—, abordó el estudio de la naturaleza americana como un proyecto personal:

Llegué a la Asunción, capital del Paraguay, donde supe que no había tales portugueses esperando, ni noticia de ellos, por cuyo motivo no quise aprontar cosa alguna ni hacer el menor costo, porque además yo sospechaba, con bastante fundamento, que dichos portugueses tardarían en llegar y que por consecuencia mi demora en el Paraguay sería dilatada. No se me había dado instrucción para este caso, y me vi precisado a meditar sobre la elección de algún objeto que ocupase mi detención con

\footnotetext{
34 Moncada, 1994, 91-92; Meza, 2009.

35 Pagazaurtundúa, 1797.

36 López de la Cámara Alta, 1757.

37 González, 1766.

38 Mascaró, 1781.

39 Crame, 1780.
} 
utilidad. Desde luego vi que lo que convenía a mi profesión y circunstancias era acopiar elementos para hacer una buena carta o mapa, sin omitir lo que pudiera ilustrar la geografía física, la historia natural de las aves y cuadrúpedos, y finalmente lo que pudiera conducir al perfecto conocimiento del país y sus habitantes. ${ }^{40}$

Debido a tales circunstancias, Azara combinó sus tareas demarcadoras de las fronteras hispano-lusas con las observaciones del clima, vientos de la región, disposición y calidad de los terrenos, accidentes topográficos, curso de los ríos y anomalías climáticas. Sus obras naturalistas, exentas de la imposición gubernativa de secreto estatal, fueron canalizándose progresivamente hacia el dominio público y alcanzaron una gran difusión en Europa. Para producirlas, Azara se valió de la información proporcionada por sus subordinados y cooperantes, así como por los clérigos establecidos en las misiones de la zona; también de la encontrada por él mismo en documentos históricos de los archivos municipales, informes oficiales de otros funcionarios e ingenieros, relaciones geográficas y de viajes y obras de geografía e historia natural; por último, de la extraída a través de las encuestas realizadas a los habitantes de los territorios y de sus propias observaciones personales. ${ }^{41}$ Esta ardua labor se sustentaba en el reparto de tareas, la delegación de trabajos a sus colaboradores, la remisión de la información recogida a una cabeza que la analizara - en este caso, el propio Azara - y la selección de la más relevante para los fines propuestos. En todo ello era fundamental el contraste del trabajo propio con otros ajenos, lo que estaba al alcance por medio del intercambio oral y epistolar con otros personajes relevantes de la administración y del mundo científico-técnico.

Otro participante en la misma expedición demarcadora fue el ingeniero militar Juan Francisco Aguirre. Éste se trasladó a las regiones australes del virreinato del Río de la Plata, expuestas a las ambiciones expansionistas de los ingleses; allí efectuó observaciones climáticas y mediciones de la dirección y fuerza de los vientos, las precipitaciones y la temperatura del aire con instrumentos meteorológicos. Su obra ${ }^{42}$ incluía datos sobre accidentes geográficos, descripciones de las realidades naturales de las zonas visitadas y comentarios sobre las condiciones climáticas de éstas.

40 Azara, 1969, 41-42 (la obra se publicó por primera vez en francés, en el año 1809).

41 Véase Campal, 1969.

42 Aguirre, 1783. 
Los colectivos de funcionarios reales e ingenieros militares, en definitiva, se implicaron en tareas de reconocimiento del clima y en otras cuestiones que relacionaban dicho fenómeno con otros de signo natural y moral. El clima formaba parte de sus averiguaciones, como un asunto más a tratar de entre los muchos que interesaban a las autoridades para el buen gobierno y mantenimiento del imperio. Y el saber adquirido consistió en una práctica colectiva en la que se compartieron objetivos, temas y consensos sobre lo que había que observar y la manera de hacerlo.

La puesta en marcha de las correspondientes labores estaba asegurada por la obediencia de aquellos personajes a las leyes y ordenanzas reales. En tanto que la minuciosidad del trabajo efectuado era consecuencia de la cantidad de tiempo empleada y de la ayuda prestada por grupos de colaboradores, además de la información acumulada y de la propia agilidad interna con la que ésta se transmitía. Las tareas en cuestión se hacían notar mientras durasen los encargos recibidos y se agotase el tiempo de estancia de los artífices de la práctica climatológica en sus respectivos destinos. Concluidas las labores, los resultados se ponían en conocimiento de las autoridades que habían de tomar las decisiones oportunas.

Los funcionarios e ingenieros al servicio de la corona ejercieron en todos los virreinatos hispanoamericanos. Hicieron acto de presencia tanto en el escenario urbano como en el rural, pero adquirió una especial importancia y atención el segundo. Su mayoritaria pertenencia a la milicia se explica por la idoneidad del estamento castrense para cumplir las exigencias gubernamentales; y también porque, tras la expulsión de los jesuitas de los dominios de la corona española, fueron ellos, junto a los miembros de otras congregaciones religiosas, quienes se hicieron cargo del control administrativo, económico y educativo de los territorios.

Respecto al género de los documentos comentados, destacó el de las relaciones geográficas e históricas, lo que concuerda con el interés que dichas obras suscitaban entre quienes debían hacerse cargo del ordenamiento de los territorios y del dominio político de sus habitantes. Casi todos los escritos mencionados se redactaron en castellano, lengua que, desde la llegada de los españoles a las costas americanas a finales del siglo XV, se convirtió en el vehículo ideal para difundir unos conocimientos que no encontraban referencia en los autores clásicos y cuyo acceso era viable para un público de variada condición social, cultural y académica. 


\section{Contenido climatológico de los documentos}

Los trabajos climatológicos de los funcionarios virreinales se inscribieron en el seno de un estudio amplio y minucioso de las características geográficas del territorio, las peculiaridades morales de los habitantes y la interacción entre los fenómenos naturales y los seres vivos. El modelo narrativo y cognoscitivo ${ }^{43}$ más recurrente era el proporcionado dos siglos atrás. Las páginas de los textos contenían vocablos de uso corriente que se referían al clima y a sus características locales o regionales; y estaban impregnados de adjetivos y adverbios que hacían referencia a impresiones sensitivas y a valoraciones elogiosas o vituperantes de aquel fenómeno. Hacia la última treintena del siglo, algunos autores incluyeron datos cuantitativos en sus escritos; con ello, dejaron de lado los enfoques y matices antropomórficos de la naturaleza y sus descripciones adquirieron mayor sobriedad y precisión; y también incrementaron su capacidad para obtener e intercambiar conocimientos de forma inequívoca y de obtener la comprensión de los lectores no especializados.

Fuera cual fuese la modalidad de sus observaciones climáticas, los funcionarios reales atendieron a asuntos como los siguientes: tipos de seres vivos que poblaban un territorio o localidad, costumbres de sus habitantes, enfermedades y epidemias que los asolaban, cultivos, características orográficas del terreno, posición astronómica de éste, sucesiones estacionales, temporadas y regímenes de lluvias, presencia de bosques y masas de agua, humedad del aire, grados de calor, vientos, precipitaciones, causas de las modificaciones atmosféricas, etc. Además, efectuaron clasificaciones y comparaciones de los climas y se interesaron especialmente por aquéllos que eran aptos para la vida, la instalación de asentamientos, los cultivos y ganados, la salud de los habitantes, el gobierno del país y el progreso educativo, social y económico de los habitantes. Véanse algunos ejemplos de esto.

La obra de Dionisio de Alsedo sobre Guayaquil se inspiró en la expedición geodésica de La Condamine y tenía como objeto elaborar un mapa descriptivo del territorio. Dos de sus capítulos trataban de las alimañas y plagas características del clima caluroso y húmedo, el efecto que sobre ellas ejercía la estación invernal, las descripciones físicas y algunos datos agrícolas.

43 Particularmente Acosta, 1590. 
En cuanto a su descripción de Quito, Alsedo superó en minuciosidad a muchas de las que se habían escrito antes. Se trataba de una obra puramente geográfica, compuesta para satisfacer el ansia de dar a conocer el país donde el autor pasó gran parte de su vida y ejerció varios cargos oficiales. Alsedo señaló los productos naturales de cada región y completó la información con observaciones físicas y notas históricas de ciudades y pueblos. Atribuyó la benignidad del clima de Quito a la proximidad de las cadenas montañosas, permanentemente nevadas. Seguidamente, puso de relieve la influencia de la altura en la temperatura del aire. También observó algunos fenómenos atmosféricos violentos y caracterizó y delimitó temporalmente las estaciones del año. El trabajo de Alsedo, en suma, se caracterizó por la relación entre el clima y el tamaño, la forma, la distancia y la orientación del territorio respecto al Sol; las características geográficas y naturales de la región; la salud y el carácter de los habitantes; y la aparición de plagas y enfermedades estacionales. Por lo demás, efectuó descripciones climáticas, buscó explicaciones causales del clima y sostuvo de dicho fenómeno tenía un carácter fijo y regular.

En la última parte de su obra, Blas Joaquín Brizuela hizo una descripción del territorio explorado por Matorras y empleó calificativos elogiosos al referirse al paisaje y al ambiente natural del Chaco. Escribió que el temple de la región era cálido y seco, aunque durante el tiempo de los mayores calores soplaban vientos del sur que refrescaban la tierra ${ }^{44}$ Brizuela se refirió al clima en términos de unos parámetros puramente sensoriales, según la experiencia propia y ajena; lo puso en relación con el entorno y recurrió a términos sencillos del lenguaje común para describirlo. ${ }^{45}$

Juan del Pino Manrique abordó asuntos como la naturaleza de los pobladores indígenas de la provincia de Tarija y las causas de su pobreza. El autor no desaprovechó la ocasión para escribir acerca del buen temple de la zona, la fertilidad del terreno y la explotación de sus recursos naturales. El plan del trabajo fechado en 1787 era el siguiente: historia de la ciudad de Potosí desde su descubrimiento por los españoles en 1546 hasta el siglo XVIII; gobierno, población, razas e instituciones; situación geográfica, edificios públicos de interés, partidos y sus riquezas naturales principales; economía y renta de los habitantes, minas, beneficios de la plata; y agricultura. Las noticias sobre los climas de las poblaciones adyacentes

44 Brizuela, 1776, 149.

45 Penhos, 2005, 32-44. 
eran bastante escuetas e iban acompañadas de calificativos como «benigno», «insano», «frío», «cálido», etc. Así, hablaba del rigidísimo clima de Porco, del clima algo más benigno de Cayza, del temperamento sano de Potosí, del temperamento cálido y abundante en maíces y frutas de Toropalca, del clima gélido y estéril de Tomabe, etc. Manrique, pues asociaba la esterilidad de la tierra al clima frío y la fertilidad al cálido, y el interés práctico de su conocimiento residía en la rentabilidad comercial de los frutos de la tierra.

Gonzalo de Doblas estimó que el extrañamiento de la Compañía de Jesús acarreó algunos males a la provincia de Misiones. Así, la población disminuyó y la producción se vio mermada a causa de la incompatibilidad entre el nuevo régimen impuesto en la zona y el genio desidioso y apático de sus habitantes; y, tras descubrir los defectos del gobierno económico impuesto desde la metrópoli, propuso otro que era en todo análogo al que en su día establecieron los jesuitas. En una línea muy similar a la trazada por Manrique, Doblas se extendió en la descripción física del territorio y sus particularidades naturales, estimó que el temperamento era benigno y sano, sin calores excesivos, y observó que el aire era húmedo, debido a la existencia de muchos bosques y ríos.

Francisco de Viedma, por su parte, dedicó palabras elogiosas al clima de la provincia de Santa Cruz de la Sierra:

El temperamento es sumamente benigno: pues, aunque por su situación en la zona tórrida debiera ser muy ardiente, la elevación del terreno e inmediación a la cordillera, que siempre mantiene nieve, le proporciona en todas las estaciones una suave primavera; de modo que muy poca variedad se halla del invierno a lo riguroso del estío, sin necesidad de mudar vestido. Bien es verdad que en el invierno suelen caer algunas heladas, pero luego que sale el Sol, se desatan y vuelven en rocío. ${ }^{46}$

Asimismo, aportó datos sobre el régimen de lluvias y vientos, las enfermedades estacionales y los frutos característicos. Teniendo en cuenta la fertilidad del suelo, Viedma abogó por que las autoridades metropolitanas y virreinales dedicaran más atención al desarrollo de la agricultura, ya que ésta sería una de las actividades que más contribuiría al apoyo y sostenimiento del país. Caracterizó el clima de la zona como ardiente, pero sano, y lo vinculó a la fertilidad del terreno. ${ }^{47}$

46 Viedma, 1788, 421.

47 Ibidem, 517-542. 
Los ingenieros militares, en otro orden de cosas, se ocuparon de asuntos climatológicos similares a los atendidos por los funcionarios reales y efectuaron clasificaciones y comparaciones de los climas. También se guiaron por el modelo literario de Acosta, pero aportaron más datos cuantitativos e instrumentales que los anteriores y su lenguaje estaba más despojado aún de connotaciones antropomórficas. De forma primordial, enfocaron sus miras hacia los climas idóneos para el fomento urbanístico, la ubicación de instalaciones defensivas, la existencia de productos naturales de probada rentabilidad comercial y la planificación agropecuaria. Se comentan a continuación algunos ejemplos de esto.

Francisco Requena escribió sobre la calidad de los terrenos de Guayaquil, sus características orográficas, la salubridad y humedad del aire, las costas, los ríos, la estación de las lluvias y la incidencia de éstas en la agricultura y en la proliferación de alimañas. Construido su relato a base de apreciaciones cualitativas, al autor le llamó la atención el vínculo entre la humedad, el calor y el estancamiento de la atmósfera, por una parte, y la salud, las enfermedades y la aparición de plagas, por otra. En función de ello, calificó el clima de húmedo, caluroso y malsano. También se refirió al carácter supuestamente indolente de los habitantes del país:

Las lluvias e inundaciones del invierno, las vastas lagunas que dejan en el verano y la abundancia de los ríos, hacen el país muy húmedo, principalmente en los meses de enero hasta junio que dura la primera estación. El calor de este tiempo, la mucha humedad y el reposo ordinario de la atmósfera, sin viento que arrastre las exhalaciones infestadas de las aguas dormidas, por lo bajo del terreno, lo hacen malsano. En tiempo de la conquista dice Herrera no llegaban a 50 años los habitadores; en el día es raro el octogenario que se encuentra, pero viven algo más que entonces. Es verdad que hay pocos descendientes de los que encontraron nuestros primeros españoles, y que si es menos enfermiza lo causa el poco más cultivada que está la provincia y lo desmontada que se halla ahora: no obstante esto, los vapores infectos detenidos y la poltronería y pereza con que viven los más de los naturales sin habituarse al trabajo, los hace no gozar toda la salud que podrían disfrutar quitados estos dos agentes. Así perecen a la violencia de toda especie de fiebres intermitentes, exhalando por la continua transpiración y sudor el jugo nutricio, al paso que enflaquecidos y debilitados los órganos internos, encuentran por las fiebres laxadas entrada a las vísceras las causas fétidas externas. ${ }^{48}$

A Pagazaurtundúa, por otro lado, le interesaba el clima de la zona por su relación con las cosechas y los ganados; en función de ello calificó el clima de benigno:

48 Requena, 1774, 32. 
El temperamento es muy benigno: abundan en todo género de ganado, siendo el principal consumo de carneros, que se hace en México, y sus inmediaciones, producto de Nuevo México, y Nueva Vizcaya: las cosechas de trigo, cebada, y maíz son de la mayor consideración en cuanto a los dos primeros granos; pero la del $3 .^{\circ}$ es abundantísima, con cuya harina y masa hacen tortillas para suplemento (que también se hace muy exquisito) y atole, en lugar de chocolate. ${ }^{49}$

Con sus trabajos naturalistas, en fin, Félix de Azara indagó en las causas de la diversidad climática del virreinato del Río de la Plata y encontró una relación directa entre los climas y los vientos. Respecto a éstos, estableció una clasificación, según su procedencia, frecuencia y duración:

Se dice ordinariamente en el país, y con razón, que hace siempre frío cuando el viento sopla del Sur o Sudeste, y calor cuando sopla del Norte. En efecto, el calor y el frío parecen depender tanto o más de los vientos que de la situación o de la declinación del Sol. Los vientos más frecuentes son el Este y el Norte. Si se deja sentir el del Sur es, a lo sumo, en una doceava parte del año, y si se inclina hacia el Sudeste, deja el cielo despejado y sereno. Apenas se conoce el viento Oeste, como si la cordillera de los Andes lo detuviera a más de 200 leguas de distancia, y si se siente algunas veces, no dura más de dos horas..$^{50}$

Azara combinó sus razonamientos con las medidas cuantitativas de la temperatura y las observaciones cualitativas. Durante sus estancias estivales e invernales en Asunción, efectuó registros máximos y mínimos de la temperatura del aire con un termómetro de escala Fahrenheit. Además, dio cuenta de algunas alteraciones climáticas singulares y sus consecuencias para las plantas. Al no disponer de aparatos adecuados en Buenos Aires, Azara esbozó una idea aproximada de su clima mediante observaciones de las manifestaciones del frío y el calor, los vientos y las lluvias, y lo comparó con el de Asunción:

En Buenos Aires yo carecía de termómetro para poder observar los puntos extremos de frío y calor, pero no hay duda de que el calor es menor, dada la latitud de $34^{\circ} 36$ 28. En cuanto al frío, es igualmente mayor que en la Asunción, y se considera como un invierno ordinario aquel que no cuenta más de tres o cuatro días si el fenómeno se verifica con más frecuencia. Aunque los vientos siguen la misma regla que en la Asunción, he observado que tienen tres veces más fuerza; que los de Poniente soplan con más frecuencia, que los del Sur traen siempre la lluvia en invierno y nunca en verano; que son menos violentos en otoño y que en la primavera y verano son más seguidos y más violentos; que levantan nubes de polvo, que a veces ocultan al Sol

49 Pagazaurtundúa, 1797. La cita se ha extraído de Moncada Maya, 2003.

50 Azara, 1969, 54 
y que nunca dejan de incomodar mucho, ensuciando las ropas, las casas y las habitaciones. Los vientos más fuertes son los del Sudoeste a Sudeste. Los huracanes son raros, pero los hay algunas veces como el de 14 de mayo de 1799, que destruyó la mitad del pueblo de Atira, en el Paraguay, mató treinta y seis personas, volcó muchas carretas y cortó la cabeza a un caballo que estaba amarrado por el cuello. El mismo año hubo otro, el 18 de septiembre, que arrojó a la costa del puerto de Montevideo ocho grandes buques y muchos pequeños..$^{51}$

Otro de los recursos metodológicos utilizados por Azara fue el del recuento numérico de los objetos a estudiar y la elaboración de tablas. Así, hizo una lista que agrupaba las naciones indias del Gran Chaco, su estatura media en pies y pulgadas y su número de habitantes; otra sobre la población de los partidos y pueblos del Paraguay, fechada en 1785, y dividida según el sexo y el origen; finalmente, aportó una tabla, referida al año 1781, sobre los bienes extractivos de la región y en la que consignaba las cantidades y precios que entonces tenían. No se han encontrado, sin embargo, tablas meteorológicas ni correlaciones explícitas entre las tablas demográfico-económicas anteriores y las características climáticas del país. Apenas se han visto pasajes referidos a la relación entre el clima y la salud, salvo un lacónico comentario referido a la humedad característica de la zona:

Siempre la atmósfera está húmeda y estropea los muebles, sobre todo en Buenos Aires, donde las habitaciones expuestas al Sur tienen siempre el piso húmedo. Los muros que tienen la misma exposición están cubiertos de césped y musgo, y el lado de los techos que se encuentran en este caso se halla cubierto de hierbas frondosas, altas, casi de tres pies, de manera que es necesario limpiarlos cada dos o tres años para evitar las goteras y filtraciones. Pero nada de esto perjudica a la salud. ${ }^{52}$

Y otro, al final de la sección, dedicado a los climas y los vientos:

Por lo que se refiere a la salud, se puede asegurar que en el mundo entero no hay un país más sano que el que estoy describiendo. La vecindad misma de los lugares acuáticos y de terrenos inundados, que se encuentran frecuentemente, no altera en nada la salud de los habitantes..$^{33}$

El aragonés recurrió al método comparativo y a la descripción y clasificación de los fenómenos meteorológicos para exponer la realidad climá-

\footnotetext{
51 Ibidem.

52 Ibidem.

53 Ibidem, 56
} 
tica de Paraguay. Y estableció una graduación del frío, la humedad del aire y la fuerza de los vientos en función de la altitud del territorio, en lugar de su latitud:

De todo esto parece se puede concluir que el frío, la humedad de la atmósfera y la fuerza de los vientos aumentan gradualmente desde la Asunción hasta Buenos Aires en razón de la altitud, que es la única causa visible que puede ocasionar la alteración. Se puede pensar, por la misma razón, que a medida que nos aproximamos al estrecho de Magallanes todos estos fenómenos deben adquirir más fuerza y los vientos deben de ser allí muy violentos. Los mismos efectos no han tenido lugar, en lo relativo al trueno y al rayo, tan terribles en el Paraguay, como en Buenos Aires, y hasta casi me parecen ser menos considerables en el Río de la Plata. Todo debe ser al revés si se dirige la marcha desde el Paraguay hacia el Norte, y yo creo que la humedad y la violencia de los vientos son allí, a latitud igual, más considerables que aquí.

En cuanto al frío, nadie duda que el hemisferio austral sea más frío en la misma latitud que el del Norte. Sin embargo, [...] el frío en este país parece depender más de los vientos que del territorio y de la distancia al Sol. ${ }^{54}$

Azara, en fin, contempló la naturaleza americana como un mundo fijista, finalista y creacionista. Por eso, y por suponer que la variedad climática seguía una gradación exacta que dependía de la latitud, se permitió efectuar observaciones del clima sólo en dos ciudades (Asunción y Buenos Aires) y sus alrededores.

En el mismo contexto expedicionario en que se desenvolvió Azara, Juan Francisco Aguirre proporcionó datos instrumentales sobre el calor y la humedad atmosférica, efectuó observaciones sobre el estado del cielo y registró los vientos imperantes de cada zona; de todo ello esbozó un cuadro de las características climáticas de diversas localidades y regiones australes del Río de la Plata y las relacionó con la salubridad del aire, las producciones vegetales, el carácter moral de los habitantes y las enfermedades endémicas y estacionales.

\section{Conclusiones}

Los trabajos climatológicos de los funcionarios virreinales consistieron en estudios de carácter ambientalista sobre el territorio, sus habitantes y la relación entre el clima y los seres vivos. Estos personajes efectuaron

54 Ibidem, 55-56. 
clasificaciones y comparaciones de los climas (benignos e insanos; secos y húmedos; calurosos y fríos) y se interesaron por los que eran aptos para la vida, la instalación de asentamientos, el fomento agropecuario, la salud de los habitantes, el control político sobre éstos y su progreso educativo y socioeconómico.

Los ingenieros militares, por su parte, se subsumieron en la misma corriente que los anteriores, se ocuparon de asuntos climatológicos similares y ensayaron análogas clasificaciones y comparaciones climáticas. Enfocaron sus miras hacia los climas idóneos para el fomento urbanístico, la ubicación de instalaciones defensivas, la existencia de productos naturales de probada rentabilidad comercial y la planificación agropecuaria.

Estaba muy extendida entre unos y otros la idea de que el clima de una localidad o región era fijo y seguía patrones repetitivos. Saber algo acerca de los regímenes eólicos e hídricos, las alternancias estacionales y los cambios usuales de frío y calor, facilitaba las labores de agricultores, ganaderos y médicos. Incluso se estimaba que los fenómenos atmosféricos inusitados se repetían y eran propios de un clima particular. Estacionalidad, periodicidad y utilitarismo, pues, fueron las connotaciones características del clima que más destacaron los miembros de las redes informativas que operaron en los virreinatos.

Estos personajes compartieron procedimientos de investigación, modelos literarios y códigos de comunicación que les permitían adquirir, compartir y transmitir conocimientos de forma inequívoca. Hacia el final de la centuria, algunos de ellos (Juan Francisco Aguirre y Félix de Azara) hicieron referencias a medidas instrumentales de la temperatura; también obtuvieron los valores extremos de esa variable y mostraron interés por los agrupamientos tabulares. Con estas prácticas pretendían ahorrar tiempo y esfuerzo y repetir las experiencias en condiciones similares. Gracias a la evidencia de los números, además, otorgaron más fiabilidad y uniformidad al discurso científico y mostraron las concordancias y desviaciones de los datos. De haber efectuado registros prolongados y uniformes, y de haber calculado los valores medios de las variables, tal vez hubiesen profundizado más en la búsqueda de regularidades y correlaciones climáticas y en la comparación y clasificación de los climas. Pero no hay pruebas de que alguno de los autores referidos procediese de tal modo.

Recibido el 23 de agosto de 2012

Aceptado el 6 de febrero de 2014 


\section{Bibliografía}

Acosta, José: Historia natural y moral de las Indias, en que se tratan las cosas notables del Cielo, y elementos, metales, plantas y animales dellas; y los ritos, ceremonias, leyes y gobierno y guerras de los indios, Sevilla, Imprenta de Juan de León, 1590.

Aguirre, Juan Francisco: «Diario» [1783], Revista de la Biblioteca Nacional, XVII-XVIII, Buenos Aires, 1947-1948.

Aguirre, Eduardo: «Una hipótesis evolucionista en el siglo XVI. El padre Acosta y el origen de las espacies americanas», Arbor, 37, Madrid, 1957, 176-187.

Alsedo y Herrera, Dionisio de: Compendio histórico de la provincia, partidos, ciudades, astilleros, ríos y puerto de Guayaquil, en las costas del mar del Sur [1741], ed. facsimilar, Madrid, 1946.

Alsedo y Herrera, Dionisio de: Descripción geográfica de la Real Audiencia de Quito [1766], reedición en Madrid, Imprenta de Fortanet, 1915.

Alsedo y Herrera, Dionisio de: «Descubrimientos y etimologías de los nombres de Falkland y Malvinas», en «Continuación del comento anual, político y geográfico y de la América Septentrional distinguida con el renombre de Nueva España, 1771», Biblioteca Nacional / Madrid, Mss. 20199, 1-41.

Altolaguirre y Duval, Ángel de: Relaciones geográficas de la gobernación de Venezuela, Caracas, Ediciones de la Presidencia de la República de Venezuela, 1954.

Álvarez Barreiro, Francisco: «Descripción de las provincias internas de Nueva España, 1729», citado en Moncada Maya, José Omar, 1994, 123.

Amat y Junyent, Manuel: «Historia Geográphica e Hydrográphica, con Derrotero General correlativo al Plan del Reyno de Chile, 1775», Biblioteca Nacional / Madrid, Mss. 13970.

Andía y Varela, José: «Relación del viaje hecho a la isla de Amat y sus adyacentes, 1774», Biblioteca Nacional / Madrid, Mss. 1999.

Azara, Félix de: Viajes por la América Meridional, que contienen la descripción geográfica, política y civil del Paraguay y del Río de la Plata [1847], reedición en Madrid, Espasa Calpe, 1969.

Bowler, Peter: Historia Fontana de las Ciencias Ambientales, México, Fondo de Cultura Económica, 1998.

Brizuela, Blas Joaquín: Diario de Matorras [1776], reedición en Buenos Aires, Imprenta del Estado, 1836.

Calderón Quijano, José Antonio: Los virreyes de Nueva España en el reinado de Carlos III, Sevilla, Escuela de Estudios Hispano-Americanos, 1967.

Campal, Esteban: Azara y su legado al Uruguay, Montevideo, Ediciones de la Banda Oriental, 1969. 
Capel, Horacio: «Geografía y cartografía», en Sellés, Manuel, José Luis Peset y Antonio Lafuente: Carlos III y la ciencia de la Ilustración, Madrid, Alianza, 1988, 99-126.

Capel, Horacio: «Las Academias de Ingenieros», en Ibidem, 187-204.

Capel, Horacio, Joan Eugeni Sánchez y José Omar Moncada Maya: De Palas a Minerva. La formación científica y la estructura institucional de los ingenieros militares en el siglo XVIII, Barcelona, CSIC-Serbal, 1988.

Capel, Horacio y Vicente Casals Costa: «Los ingenieros o el matrimonio de la ciencia con las artes útiles», en Peset, José Luis (dir.), Historia de la Ciencia y la Técnica en la Corona de Castilla, siglo XVIII, IV, Salamanca, Junta de Castilla y León-Caja Duero, 2002, 569-602.

Capel, Horacio: «El ingeniero militar Félix de Azara y la frontera americana como reto para la ciencia española», en Varios Autores, Tras las huellas de Félix de Azara (1742-1821). Jornadas sobre la vida y la obra del naturalista español Don Félix de Azara celebradas en Madrid los días 19 al 22 de octubre de 2005, Huesca, Diputación de Huesca, 2005, 83-132.

Costanzó, Miguel: Diario del Viage de Tierra hecho al Norte de la California [1770], reedición en Berkeley, University of California, 1911.

Crame, Agustín: «Discurso político sobre el fomento de la isla de Cuba, 1780», Biblioteca del Palacio Real / Madrid, 1780, Mss. 2827.

Doblas, Gonzalo de: Memoria histórica, geográfica, política y económica sobre la Provincia de Misiones de Indios Guaraníes [1785], reedición en Buenos Aires, Imprenta del Estado, 1836.

García y García, José Antonio: Relaciones de los virreyes del Nuevo Reino de Granada, Nueva York, Hallet \& Breen, 1869.

Glacken, Clarence: Huellas en la playa de Rodas. Naturaleza y cultura en el pensamiento occidental desde la Antigüedad hasta fines del siglo XVIII, Barcelona, El Serbal, 1996.

González, Juan de Dios: «Reconocimiento de la provincia de Yucatán y parte de la costa de Honduras, 1766», Servicio Histórico Militar / Madrid, Documentos Originales, 5-3-9-9.

Guijarro Mora, Víctor y Leonor González de la Lastra: La quimera del autómata matemático, Madrid, Cátedra, 2010.

Guimerá, Agustín (coord.): El reformismo borbónico, Madrid, Alianza, 1996.

Kamen, Henry: Imperio: la forja de España como nación, Madrid, Santillana, 2003.

Lafora, Nicolás: «Viaje a los presidios internos de la América septentrional, 17661768», en Viajes por Norteamérica, Madrid, Aguilar, 1958.

Lafuente, Antonio y Antonio Mazuecos: Los caballeros del punto fijo, Barcelona, Serbal-CSIC, 1978.

Lafuente, Antonio y José Luis Peset: «Militarización de las actividades científicas en la España ilustrada (1726-1754)», en Peset, José Luis y otros, La ciencia moderna y el Nuevo Mundo, Madrid, CSIC, 1986, 127-147. 
Lafuente, Antonio y José Luis Peset: «Las actividades e instituciones científicas en la España ilustrada», en Sellés, Manuel, José Luis Peset y Antonio Lafuente, Carlos III y la ciencia de la Ilustración, Madrid, Alianza, 1988, 29-80.

Lafuente, Antonio y José Sala Catalá: Ciencia colonial en América, Madrid, Alianza, 1992.

Lafuente, Antonio y Leoncio López-Ocón Cabrera: «Tradiciones científicas y expediciones ilustradas en la América hispana del siglo XVIII», en Saldaña, Juan José (coord.), Historia social de las ciencias en la América Latina, México, UNAM-Porrúa, 1996, 247-281.

Latour, Bruno: Ciencia en acción. Cómo seguir a los científicos e ingenieros a través de la sociedad, Barcelona, Labor, 1992.

Laviana Cuetos, María Luisa: La descripción de Guayaquil por Francisco Requena, 1774, Sevilla, CSIC, Escuela de Estudios Hispano-Americanos, 1984.

Lohmann Villena, Guillermo: Las relaciones de los virreyes del Perú, Sevilla, Escuela de Estudios Hispano-Americanos, 1959.

López de la Cámara Alta, Agustín: Descripción del Nuevo Santander [1757], reedición en México, UNAM, Instituto de Investigaciones Históricas, 2006.

López Pozo, Francisco: Las Leyes de Indias, Córdoba, Publicaciones Obra Social y Cultural CAJASUR, 1995.

Lozano, Pedro: Descripción corográfica del terreno, ríos, árboles y animales de las dilatadísimas provincias del Gran Chaco, y de los ritos y costumbres de las innumerables naciones bárbaras e infieles que la habitan. Con una cabal relación histórica de lo que en ellas han obrado para conquistarlas algunos gobernadores, ministros reales y misioneros jesuitas para reducirlas a la fe del verdadero Dios [1773], reedición en Tucumán, Instituto de Antropología, 1941.

Martínez Sanz, José Luis: Relaciones científicas entre España y América, Madrid, MAPFRE, 1992.

Mascaró, Manuel: «Descripción y actual estado del pueblo y misiones de Arizpe, 1781», citado en Moncada Maya, José Omar, 1994, 125.

Meza, Robinson: «Visión de la frontera Norte de Nueva España por Nicolás de Lafora (1766-1768)», Presente y Pasado. Revista de Historia, 27, México, enero-junio de 2009, 11-30.

Middleton, William Edgar Knowles: Invention of the Meteorological Instruments, Baltimore, Johns Hopkins Press, 1969.

Moncada Maya, José Omar: El ingeniero Miguel Costanzó. Un militar ilustrado en la Nueva España del siglo XVIII, México, Instituto de Geografía, UNAM, 1994.

Moncada Maya, José Omar: «Una descripción de las Provincias Internas de la Nueva España a finales del siglo XVIII. La descripción del ingeniero militar Juan de Pagazaurtundúa», Biblio 3W. Revista Bibliográfica de Geografía 


\section{JUAN ALBERTO MOLINA GARCÍA}

y Ciencias Sociales, 436, 2003, http://www.ub.es/geocrit/b3w-436.htm, 26 de octubre de 2013.

Muñoz Pérez, José: «Los historiadores primitivos de Indias y el pensamiento geográfico», en Solano, Francisco de y Francisco del Pino, América y la España del siglo XVI, I, Madrid, CSIC, Instituto Gonzalo Fernández de Oviedo, 1982, 135-188.

Pagazaurtundúa, Juan de: «Sucinta Descripción de las Provincias Internas, 1797», Servicio Histórico Militar / Madrid, Documentos Originales, 5-2-1-7

Penhos, Marta: Ver, conocer, dominar. Imágenes de Sudamérica a finales del siglo XVIII, Buenos Aires, Siglo XXI, 2005.

Peset, José Luis y otros: La ciencia moderna y el Nuevo Mundo, Madrid, CSIC, 1986.

Peset, José Luis (dir.): Historia de la Ciencia y la Técnica en la Corona de Castilla, siglo XVIII, IV, Salamanca, Junta de Castilla y León-Caja Duero, 2002.

Pino Manrique, Juan del: Descripción de la Provincia y Ciudad de Tarija [1785], reedición en Buenos Aires, Imprenta del Estado, 1836.

Pino Manrique, Juan del: Descripción de la villa de Potosí y de los partidos sujetos a su intendencia, [1787], reedición en Buenos Aires, Imprenta del Estado, 1836.

Radaelli, Sigfrido (comp.): Memorias de los virreyes del Río de la Plata, Buenos Aires, Bajel, 1914.

Requena, Francisco: «Descripción histórica y geográfica de la provincia de Guayaquil en el virreinato de Santa Fe, 1774», en Laviana Cuetos, María Luisa: La descripción de Guayaquil por Francisco Requena, 1774, Sevilla, EEHA, 1984, 25-132.

Río Sadornil, José Luis del: «Don Francisco Requena y Herrera: una figura clave en la Demarcación de los Límites Hispano-Lusos en la cuenca del Amazonas (s. XVIII)», Revista Complutense de Historia de América, 29, Madrid, 2003, 51-75.

Sargent, Frederick: Hippocratic Heritage, a History of Ideas about Weather and Human Health, Nueva York, Pergamon Press, 1982.

Schäfer, Ernst: El Consejo Real y Supremo de las Indias. Su historia, organización y labor administrativa hasta la terminación de la Casa de Austria, II, Valladolid, Junta de Castilla y León, Consejería de Educación y Cultura, 2003, 351-379.

Saldaña, Juan José (coord.): Historia social de las ciencias en la América latina, México, UNAM-Porrúa, 1996.

Sellés, Manuel, José Luis Peset y Antonio Lafuente: Carlos III y la ciencia de la Ilustración, Madrid, Alianza, 1988.

Solano, Francisco de y Fermín del Pino: América y la España del siglo XVI, I, Madrid, CSIC, Instituto Gonzalo Fernández de Oviedo, 1982. 
Solano, Francisco de y Pilar Ponce Leiva (eds.): Cuestionarios para la formación de las Relaciones Geográficas de Indias. Siglos XVI-XIX, CSIC, Madrid, 1988a.

Solano, Francisco de: Relaciones geográficas del arzobispado de México, 1743, Madrid, CSIC-Tierra Nueva e Cielo Nuevo, 1988b.

Solano, Francisco de: Relaciones Geográficas del Reino de Chile. 1756, Madrid, CSIC-Santiago de Chile, Universidad Internacional SEK, 1995.

Urteaga, Luis: «La teoría de los climas y los orígenes del ambientalismo», Geo Crítica, 99, Barcelona, 1992, http://www.ub.edu/geocrit/geo99.htm, 26 de octubre de 2013.

Valverde Pérez, Nuria: Actos de precisión. Instrumentos científicos, opinión pública y economía moral en la Ilustración española, Madrid, CSIC, 2007.

Varios Autores: Tras las huellas de Félix de Azara (1742-1821). Jornadas sobre la vida y la obra del naturalista español Don Félix de Azara celebradas en Madrid los días 19 al 22 de octubre de 2005, Huesca, Diputación de Huesca, 2005.

Viedma, Francisco de: Descripción geográfica y estadística de la provincia de Santa Cruz de la Sierra [1788], reedición en Buenos Aires, Imprenta del Estado, 1836. 